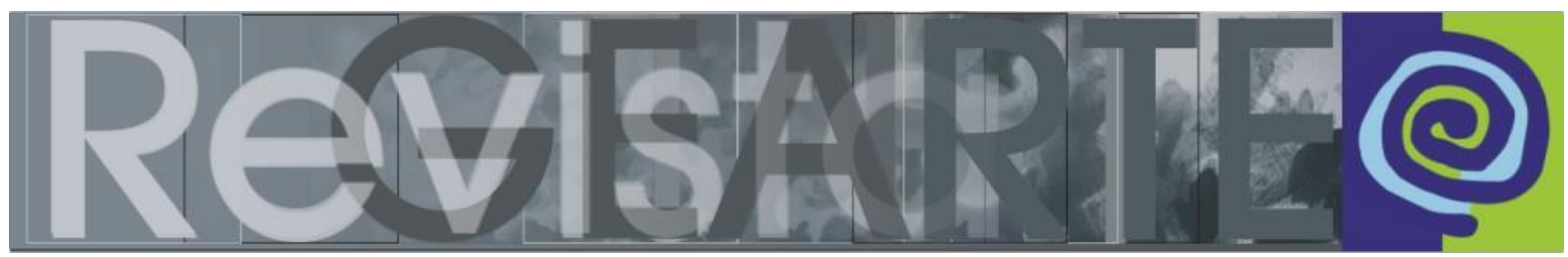

e-ISSN 2357-9854

\title{
Docência em Arte no contexto da BNCC: É preciso reinventar o ensino/aprendizagem em Arte?
}

\author{
Lucia Gouvêa Pimentel (Universidade Federal de Minas \\ Gerais - UFMG, Belo Horizonte/MG, Brasil) \\ Ana Del Tabor Vasconcelos Magalhães (Universidade Federal \\ do Pará - UFPA, Belém/PA, Brasil)
}

\begin{abstract}
RESUMO - Docência em Arte no contexto da BNCC: É preciso reinventar o ensino/aprendizagem em Arte? - Neste texto são feitas reflexões sobre a conjuntura das políticas públicas que incidem no processo das reformas curriculares que afetam o ensino/aprendizagem, a formação docente e o consequente exercício/atuação no componente curricular Arte. São discutidos os possíveis entraves na implementação da Base Nacional Comum Curricular - BNCC - Arte para Educação Infantil e Ensino Fundamental em 2017, e as interpretações que surgem sobre a BNCC - Arte para o Ensino Médio em 2018 (em fase de discussão), com ênfase para as Artes Visuais. As constantes mudanças e a velocidade com que entram em vigor sem que se tenha discussão consistente ou sejam explicitadas as razões para tal, com transparência, deixa perplexos os especialistas da área de Artes, bem como quem atua no ensino/aprendizagem em Artes Visuais no contexto escolar.
\end{abstract}

PALAVRAS-CHAVE

Ensino/Aprendizagem em Arte. Reformas curriculares. Base Nacional Comum Curricular - Arte.

ABSTRACT - Teaching Art in the context of BNCC: is it necessary to reinvent teaching/learning in arts? - This text includes reflection on the public policies that affect the process of reform of the curriculum with respect to teaching and learning, teacher training and the consequent implementation and exercise of the Art component of the curriculum. There is discussion about the potential obstacles to implementation of the Common Basic National Curriculum [BNCC in the Brazilian acronym], with emphasis on the visual arts, and with respect to: Art for Infant Education and Basic Teaching in 2017, and the subsequent interpretations of the BNCC; Art for Middle School in 2018, which is still under discussion. The constant changes, together with the speed with which they are implemented, without thorough discussion and without clear explanation of the reasoning behind them, causes confusion among Art specialists and others who are active in the teaching or learning of Visual Arts in schools. KEYWORDS

Art teaching and learning. Reform of the curriculum. Common Base National Curriculum - Art.

\section{Introdução}

A conjuntura das políticas públicas que incidem no processo das reformas curriculares da Educação Básica e do Ensino Superior vem sendo assunto premente na agenda de especialistas da área educacional. Em relação ao componente curricular Arte, as ameaças à sua obrigatoriedade na Educação Básica são destaques polêmicos após a aprovação da Base Nacional Comum Curricular - BNCC para Educação Infantil e Ensino Fundamental em 2017, e a proposta (em discussão) para 
a BNCC do Ensino Médio. Assim, algumas abordagens merecem destaque neste texto, objetivando ampliar a discussão em várias instâncias educacionais, com ênfase para o ensino/aprendizagem, a formação docente e o consequente exercício/atuação no componente curricular Arte.

Com base nos estudos das teorias de currículo e ensino/aprendizagem nas áreas de Educação e Arte, encontramos valiosas contribuições de autores que discutem a temática centrada para as tramas conduzidas nas disputas e preferências curriculares como reflexo de poder. Para Moreira e Silva (1995, p.29), "O poder se manifesta por meio das linhas divisórias que separam os diferentes grupos sociais em termos de classe, etnia, gênero etc. Essas divisões constituem tanto a origem quanto o resultado de relações de poder".

Como campo de lutas e conflitos, de construção e produção de significações e sentido, o currículo é atravessado por relações de poder, sendo necessário reconhecer as forças que agem. Assim sendo, os autores evidenciam que é importante não identificar o poder somente relacionado a pessoas ou atos legais, uma vez que isso poderia levar a negligenciar as relações de poder inscritas nas rotinas e rituais institucionais cotidianos (MOREIRA; SILVA,1995).

Se currículo for considerado "uma gama de conhecimentos e habilidades, entendimentos e qualidades que os alunos têm de desenvolver, ou adquirir" (DFE, 1995, s/p) ${ }^{1}$, questionamos: a quem cabe o poder de definir quais são esses conhecimentos, habilidades, entendimentos e qualidades?

O poder encontra-se sempre associado à legitimação do legislador. O direito de decidir sobre o que é verdadeiro e o que não é, independente do direito de decidir sobre o que é justo ou não é, segundo Lyotard (1986), vem do entrosamento entre ciência, ética e política. Considera o autor que saber e poder são duas faces de uma mesma questão: quem decide o que é saber? Quem sabe o que convém decidir?

\footnotetext{
${ }^{1}$ DEPARTMENT OF EDUCATION (DFE). The National Curriculum: Arts. London: HMSO, 1995. 
A participação coletiva na elaboração do currículo é essencial quando se considera que ele seja

\begin{abstract}
A referência social para que haja um esforço reconstrutivo pessoal e integrado que possibilite uma atitude participativa, envolvida, emocionalmente carregada d@ alun@, sendo um campo fértil para criação e construção de conhecimentos. (PIMENTEL, 1999, p.158)
\end{abstract}

No final do século XX já se afirmava que a ideia de que seriam os especialistas quem deveria fazer o currículo para que professores e alunos os cumprissem já estava ultrapassada. Especialistas são importantes e têm papel fundamental na elaboração de propostas curriculares, "mas é importante que os atores que vão atuar diretamente na prática do currículo participem de sua elaboração, uma vez que serão eles que irão vivenciar sua efetivação". (PIMENTEL, 1999, p.158)

Todo currículo é uma norma, que pode ser "aplicado" como regra obrigatória a ser cumprida, quanto como uma referência para novas propostas e ações. Nesse sentido, é necessário que haja condições para que professores e alunos possam pensar imaginativamente e possam realizar tarefas em que seu potencial seja desenvolvido, tanto criativamente quanto pessoalmente.

Sendo o currículo uma construção social e cultural, supõe-se que sua elaboração, além de ser coletiva, tenha uma dinâmica que atenda à prática cultural do contexto onde ele vai ser implantado, proporcionando o ir além. (PIMENTEL, 1999, p.158)

O currículo visa à formação de pessoas que atuarão em algum campo do conhecimento humano e que, portanto, terão que ter competência para tal. Trata-se da construção de conhecimentos específicos - e não de aquisição de conhecimento como produto pronto -, o que acarreta a necessidade de uso da imaginação para criar novas argumentações, novas alternativas de ensino/aprendizagem em Arte.

Outra reflexão trazida por Moreira e Silva (1995), que consideramos relevante para pensar a conjuntura das reformas curriculares após várias alterações na LDB no 9.394/96, é a perspectiva de investigar o currículo oficial com um foco histórico, possibilitando 
[...] uma análise que flagre os momentos históricos em que arranjos foram concebidos e tornaram-se "naturais". Desnaturalizar e historicizar o currículo existente é um passo importante na tarefa política de estabelecer objetivos alternativos e arranjos curriculares que sejam transgressivos da ordem curricular existente. (MOREIRA; SILVA, 1995, p. 31).

Nesse sentido, para que possamos entender a dinâmica das reformas curriculares em um momento histórico conturbado por políticas públicas partidárias, faz-se necessário refletir a trajetória histórica da área para entender as orientações pedagógicas de cada época. A perspectiva de integração das artes, as unidades temáticas, os objetos de conhecimentos, as relações entre Arte e as tecnologias da informação e comunicação, as competências e habilidades que deverão ser alcançadas em cada ano de ensino são questões abordadas no documento da BNCC de 2017, que merecem ser debatidas de forma crítica durante a elaboração das propostas curriculares nas escolas e em outros momentos pedagógicos. Para cada área de conhecimento há determinações que têm/terão implicações no processo de orientação das secretarias de Educação, sendo necessário o engajamento dos profissionais da área, problematizando e questionando o ensino/aprendizagem de Arte na Educação Básica.

Ana Mae Barbosa (2008) considera a memória e a história elementos indispensáveis para a consciência política do educador no processo de ensino/aprendizagem de Arte e traz importantes contribuições para entendermos a trajetória histórica da Arte na Educação. Ressalta que cada geração tem direito a reinterpretar sua herança histórica, por isso o conhecimento histórico é essencial para a formação da consciência política do indivíduo.

Suas reflexões corroboram para pensar de forma crítica o passado, avaliar o presente e projetar o futuro do ensino/aprendizagem da Arte que queremos. No entanto, o processo é lento. Entre marchas e contramarchas, as conquistas são comemoradas por poucos e ignoradas por muitos que se isolam nos espaços da sala de aula, sem considerar os movimentos políticos de seus pares e das entidades que os representam. O momento é tão crítico que precisamos resistir para existir no cenário educacional contemporâneo, superando as ameaças que surgem para o componente curricular Arte e seu ensino/aprendizagem. 
Ao longo da história, houve alteração do ensino de Arte. Na Lei oㅜ 4.024/61, havia a possibilidade de ensino/aprendizagem em Arte no currículo, no ensino primário, caso a duração fosse estendida de quatro para até seis anos. Isso seria feito para ampliar, "nos dois últimos, os conhecimentos do aluno e iniciando-o em técnicas de artes aplicadas, adequadas ao sexo e à idade" (Art. 26, Parágrafo único). No ensino de grau médio, arte é tratada como "atividades complementares de iniciação artística" (Art. 38, IV). Para estabelecimentos de ensino industrial em nível médio, o Art.50 previa a possibilidade de cursos de artesanato. Para o ensino superior, o Art. 66 refere-se ao objetivo do ensino/aprendizagem de Arte como sendo "a pesquisa, o desenvolvimento das ciências, letras e artes". A autonomia do professor é declarada no Art. 71: "O programa de cada disciplina sob forma de plano de ensino, será organizado pelo respectivo professor, e aprovado pela congregação do estabelecimento".

Na LDB no 5.692/71, Educação Artística era considerada atividade obrigatória, com característica de formação e de ação polivalente do professor, que precisava trabalhar com Artes Cênicas, Artes Plásticas e Música, mesmo sem ter formação para tal. Na LDB no 9.394/06, Arte passou a ser componente curricular, sendo tratada, portanto, como campo de conhecimento específico. Essa alteração ocorreu pela pressão do movimento político das Associações Estaduais de Arte/Educação, por intermédio da Federação de Arte/Educadores do Brasil - FAEB, que não mediu esforços para a permanência e obrigatoriedade do Ensino de Arte na Educação Básica.

Após várias solicitações de alteração, na atual LDB, de outras entidades interessadas, a redação da última alteração consta na Lei oํ 13.415, de 2017, o Art. 26, $\S 2^{\circ}$, assim disposto: "O ensino da Arte, especialmente em suas expressões regionais, constituirá componente curricular obrigatório da educação básica". E no § $6^{\circ}$ é esclarecido que "as artes visuais, a dança, a música e o teatro são as linguagens que constituirão o componente curricular de que trata o $\S 2^{\circ}$ deste artigo" (Redação dada pela Lei no $13.278 / 2016$ ). 
As conquistas do movimento político da Federação de Arte/Educadores do Brasil - FAEB foram/são imprescindíveis para garantir a permanência e obrigatoriedade de Arte no currículo escolar e provocar reflexões sobre o exercício/atuação da profissão docente na Educação Básica. Entretanto, é notório que após a aprovação e divulgação da BNCC em 2017 (Educação Infantil e Ensino Fundamental) houve/há estranhamentos em relação às orientações estruturais e pedagógicas em várias regiões do país, causando mal-estar de toda ordem.

Em função das especificidades do componente curricular Arte e o exercício da carreira docente dos egressos dos cursos de Licenciatura em Artes Visuais, Licenciatura em Dança, Licenciatura em Música e Licenciatura em Teatro, há várias dúvidas/interpretações no processo de implementação da BNCC em vigor no que diz respeito ao desenho curricular das escolas e a área de Linguagens, a formação/atuação docente, a carga horária e o direito dos egressos em realizar concursos públicos, dentre outras.

Assim, consideramos que há descompassos entre a legislação vigente e o entendimento sobre o componente curricular Arte no currículo da Educação Básica após a divulgação/implementação da BNCC para Educação Infantil e Ensino Fundamental, comprometendo sobremaneira os seus encaminhamentos teóricometodológicos, tanto no que se refere ao próprio componente curricular Arte, quanto às suas respectivas modalidades artísticas. Nesse sentido, para provocar o debate, destacamos alguns entraves, dentre muitos, na implementação da BNCC no tocante ao componente curricular Arte.

\section{Alguns entraves na implementação da BNCC para o componente curricular Arte}

O desenho curricular das escolas e a área de Linguagens

O componente curricular Arte envolve quatro modalidades artísticas que necessitam de docentes formados em suas distintas licenciaturas para atuar na Educação Básica. No entanto, rever a inserção do componente curricular Arte vinculado a área de Linguagens na BNCC requer profundas reflexões conceituais e não se muda de forma tão rápida o que foi construído anteriormente nos documentos 
oficiais oriundos do MEC. Não é nosso objetivo explicar neste texto se arte é ou não linguagem e quais as razões de estar inserida na referida área, apesar de entendermos que Arte deveria ser configurada em uma área específica de conhecimento.

A autonomia da área de $\operatorname{Artes}^{2}$, em relação aos demais componentes da área de Linguagens, se dá pelas questões complexas com que as Artes lidam, não só na nomenclatura, mas principalmente na sua composição em modalidades que, embora tenham princípios comuns, têm variedade de linha epistemológica e paradigmas conceituais que valem a pena considerar com mais profundidade. Há que se tomar toda precaução para que não aconteça a volta à época da ditadura (1964-1984), que impôs a polivalência no ensino/aprendizagem em Arte.

\section{A formação/atuação docente}

A formação de professores de Artes Visuais - como também de Dança, Música e Teatro - vem passando por reformas curriculares à luz da Resolução ํㅡㄴ 2 , de $1^{\circ}=$ de julho de 2015, que define as Diretrizes Curriculares Nacionais para a formação inicial em nível superior. A Resolução nํㅡㄴ 2 , no Art. $1^{\circ}, \S 2$, indica a obediência "às políticas públicas de educação, às Diretrizes Curriculares Nacionais, ao padrão de qualidade e ao Sistema Nacional de Avaliação da Educação Superior (Sinaes) " e docência é definida

Como ação educativa e como processo pedagógico intencional e metódico, envolvendo conhecimentos específicos, interdisciplinares e pedagógicos, conceitos, princípios e objetivos da formação que se desenvolvem na construção e apropriação dos valores éticos, linguísticos, estéticos e políticos do conhecimento inerentes à sólida formação científica e cultural do ensinar/aprender, à socialização e construção de conhecimentos e sua inovação, em diálogo constante entre diferentes visões de mundo. (BRASIL, 2015, Art. $2^{\circ}, \S 1^{\circ}$ )

Essa definição de docência é tão ampla quanto a de educação, que abrange

Os processos formativos que se desenvolvem na vida familiar, na convivência humana, no trabalho, nas instituições de ensino, pesquisa e extensão, nos

2 A área de conhecimento denomina-se Artes por englobar as diversas modalidades artísticas; o componente curricular na Educação Básica denomina-se Arte, justamente porque demanda um professor especialista para cada modalidade artística. 
movimentos sociais e organizações da sociedade civil e nas relações criativas entre natureza e cultura. (BRASIL, 2015, Art. $3^{\circ} \S 1^{\circ}$ )

Tem-se, portanto, duas definições abrangentes, mas que registram estéticas e culturas como parte tanto da formação docente quanto na educação em geral. Nesse contexto, a Base Nacional Comum Curricular terá articulação direta com a política nacional de formação dos profissionais da Educação, sendo necessário garantir o que vem preconizado em cada documento. Entretanto, ainda temos dificuldades para identificar as conexões dos conteúdos da BNCC (2017) com os conteúdos necessários à formação do Professor de Arte, em função das proposições evasivas da BNCC para Educação Infantil e Ensino Fundamental.

\title{
A carga horária para cada modalidade artística
}

No antigo documento do MEC, Parâmetros Curriculares Nacionais - Arte (1998) havia recomendação para que houvesse no mínimo duas aulas semanais e que Arte estivesse presente em todos os níveis de ensino. Além dessa recomendação, havia sugestão para desenhos curriculares, o que não se observa na BNCC em vigor.

Na BNCC (2017) é ressaltado que:

\begin{abstract}
Ao longo do Ensino Fundamental, os alunos devem expandir seu repertório e ampliar sua autonomia nas práticas artísticas, por meio da reflexão sensível, imaginativa e criativa sobre os conteúdos artísticos e seus elementos constitutivos e também sobre as experiências de pesquisa, intervenção e criação. [...] A progressão das aprendizagens não está proposta de forma linear, rígida ou cumulativa com relação a cada linguagem ou objeto de conhecimento, mas propõe um movimento no qual cada nova experiência se relaciona com as anteriores e as posteriores na aprendizagem de Arte (BRASIL, BNCC, 2017, p.195).
\end{abstract}

Assim exposto, entendemos que há necessidade de garantir uma carga horária mínima e objetos de conhecimentos que possam contemplar de forma plena o processo de ensino/aprendizagem do componente curricular Arte e suas modalidades artísticas. Deixar a critério dos sistemas e redes de ensino a efetivação das aprendizagens em Arte é flexibilizar e fragilizar demais a orientação de um documento que é de obrigatoriedade nacional, e tem como objetivo a "redução das desigualdades educacionais no Brasil e a promoção da equidade e da qualidade das aprendizagens dos estudantes brasileiros" (BRASIL, BNCC, 2017, p. 5). 
A contradição é clara: como promover aprendizagens em Arte que corroborem com a educação de qualidade para todos os estudantes brasileiros sem a obrigatoriedade, ao longo da Educação Básica, de uma área de conhecimento fundamental para a formação humana?

\section{O direito dos egressos em realizar concursos públicos específicos}

A Lei ํㅗ 13.278/2016, Art. 2º, que alterou a LDB ํo 9.394/96, determina que o "prazo para que os sistemas de ensino implantem as mudanças decorrentes desta Lei, incluída a necessária formação dos respectivos professores em número suficiente para atuar na educação básica, é de cinco anos".

As orientações pertinentes para a realização de concursos na área ainda estão assentadas na Lei ํㅜ 5.692/71, com o antigo cargo de Professor de Educação Artística, causando transtornos de toda ordem, havendo disparidades no trato em relação aos concursos para o componente curricular. As resoluções aprovadas pela Câmara de Educação Superior (CES) do Conselho Nacional de Educação (CNE), que aprovaram as diretrizes curriculares para os cursos de graduação nas suas especificidades, quais sejam: Música na Resolução CNE/CES no 2/2004; Dança na Resolução CNE/CES no 3/2004; Teatro na Resolução CNE/CES no 4/2004; Artes Visuais na Resolução CNE/CES no 1/2009, ainda não são consideradas nos concursos, implicando em orientações que afetam o direto do egresso em sua atuação docente na modalidade artística específica para a qual se especializou.

Os concursos públicos que ainda estão pautados na polivalência, bem como as instituições de ensino que a exercem estão, portanto, descumprindo a Lei, além de estarem causando prejuízo para a aprendizagem dos alunos, que têm direito à qualidade de ensino também estipulada pela Resolução CNE-CP no 2/2015.

\section{A unidade temática Artes Integradas}

A partir da premissa de que a ação artística, seja ela a elaboração de objetos ou eventos artísticos ou o refletir sobre ou fruir esses objetos ou eventos, é também elaborar uma pedagogia, produzir uma nova forma de vida, tem-se que essa nova 
forma de vida é atravessada e transversalizada pela época e pelo contexto em que se vive. $E$ isso se dá porque, além da subjetividade individual, construímos e somos parte de uma subjetividade coletiva, que é social, que nos força ao reinventar constante de nós mesmos. Cada um tem sua forma de ser, mas essa forma de ser não é sempre a mesma.

Assim, a cada produção artística estamos criando pedagogia, ou seja, estamos criando arte e formas de aprender arte, mesmo que não se tenha consciência disso. Produzir arte, portanto, é uma ação de extrema responsabilidade para o Professor de Arte na Educação Básica, uma vez que, nas aulas, pelo fazer, fruir ou contextualizar arte, novas formas de vida e de aprendizagem são criadas, e atravessam a vida dos estudantes sob sua tutela.

Consideramos que a integração entre as modalidades artísticas e entre elas e outros campos do saber só pode ocorrer se todas elas tiverem o mesmo valor ao se integrarem, caso contrário sempre haverá sobreposição de uma em detrimento das outras, que serão submissas e não poderão contribuir com a construção de conhecimento em seu campo específico.

Integrar, portanto, significa imbricar de tal forma que novos conhecimentos possam ser construídos preservando-se a potência de cada um dos campos do saber envolvidos, não havendo o mais forte e o mais fraco, mas havendo o que um e outro tem a compartilhar. Para que isso aconteça, é necessário que o estudo de cada campo artístico seja aprofundado, sob a orientação de um especialista.

\section{Algumas Considerações}

Há que se estar, portanto, em Estado de Alerta $^{3}$ para que politicas educacionais impostas sem a devida discussão tragam prejuízos ao ensino/aprendizagem em Arte e para que os próprios especialistas da área de Artes se unam, em suas diferenças

3 Estado de Alerta é o nome do I Encontro da ANPAP da região Sudeste, realizado de 15 a 18 de maio de 2018 no Museu de Arte Contemporânea em Niterói. Ver mais em: https://www.facebook.com/estadodealerta2018.anpap.rj/ 
teóricas, em torno da preservação e da ampliação do ensino/aprendizagem em Arte no contexto escolar.

Nosso interesse em apontar alguns entraves na implementação da BNCC para o componente curricular Arte não é somente para destacar os problemas que surgem. Consideramos que as orientações pedagógicas da BNCC necessitam ser debatidas, analisadas e criticadas no processo de formação docente nos cursos de Licenciatura e outras instâncias, com vistas a construir propostas pedagógicas ou curriculares que se coadunem com as realidades de cada região.

Práticas educativas planejadas exigem uma atuação docente crítica para o componente curricular Arte e suas respectivas modalidades artísticas. O debate é imprescindível diante das incertezas e dúvidas que surgem em um cenário educacional que precisamos resistir para existir ou é preciso reinventar o ensino/aprendizagem em Arte?

\section{Referências}

BARBOSA, Ana Mae. Entre memória e história. In: BARBOSA, Ana Mae (org.). Ensino da arte: memória e história. São Paulo: Perspectiva, 2008.

BRASIL. Lei no 4.024, de 20 de dezembro de 1961. Fixa as diretrizes e bases da educação nacional. Disponível em: <https://presrepublica.jusbrasil.com.br/legislacao/108164/lei-de-diretrizes-e-base-de1961-lei-4024-61>. Acesso em: 22 mai. 2018.

BRASIL. Lei $n^{\circ}$ 9.394, de 20 de dezembro de 1996. Estabelece as diretrizes e bases da educação nacional. Disponível em: <http://www.planalto.gov.br/ccivil_03/ leis/L9394.htm>. Acesso em: 16 abr. 2018.

BRASIL. Lei no 12.287, de 13 de julho de 2010. Altera a Lei no 9.394, de 20 de dezembro de 1996, que estabelece as diretrizes e bases da educação nacional, no tocante ao ensino da arte. Disponível em: <http://www.planalto.gov.br/ccivil_03/_Ato2007-2010/2010/Lei/L12287.htm>. Acesso em: 07 out. 2017.

BRASIL. Conselho Nacional de Educação. Resolução $n^{\circ}$ 2, de $1^{\circ}$ de julho de 2015. Disponível em: portal.mec.gov.br/index.php?option=com_docman\&task=doc_download Acesso em: 20 abr.2018.

BRASIL. Lei $n^{\circ}$ 13.278, de 02 de mai. 2016. Altera o § 60 do art. 26 da Lei no 9.394, de 20 de dezembro de 1996, que fixa as diretrizes e bases da educação nacional, referente ao ensino da arte. Disponível em: <http://www.planalto.gov.br/ccivil_03/_ato2015-2018/2017/lei//13415.htm>. Acesso em: 22 mai. 2018.

BRASIL. Lei no 13.415, de 16 de fevereiro de 2017. Altera a Lei no 9.394, de 20 de dezembro de 1996, que estabelece as diretrizes e bases da educação nacional, no tocante ao ensino da arte. Disponível em: <http://www.planalto.gov.br/ccivil_03/_ato2015-2018/2017/lei//13415.htm>. Acesso em: 22 mai. 2018.

BRASIL. Base Nacional Comum Curricular: Fundamentos Pedagógicos e Estrutura Geral da BNCC: versão 3, Brasília, 2017. Disponível em: <http://basenacionalcomum.mec.gov.br/images/ Acesso em: 22 mai. 2018. 
LYOTARD, Jean-François. A fenomenologia. Lisboa: Ed 70, 1986.

MOREIRA, Antonio Flávio; SILVA, Tomaz Tadeu. Sociologia e teoria crítica do currículo: uma introdução. In: MOREIRA, Antonio Flávio; SILVA, Tomaz Tadeu (org.). Currículo, cultura e sociedade. São Paulo: Cortez, 1995.

PIMENTEL, Lucia Gouvêa. Limites em expansão: Licenciatura em Artes Visuais. Belo Horizonte: C/Arte, 1999.

\section{Lucia Gouvêa Pimentel}

Professora Titular da Escola de Belas Artes da UFMG e Conselheira do Instituto Arte das Américas. Bacharel e Licenciada em Artes Visuais (UFMG), Mestre em Educação (UFMG), Doutora em Artes (USP). É líder do Grupo de Pesquisas Ensino da Arte e Tecnologias Contemporâneas (CNPq), Editora da Revista CLEA, Coordenadora da Coleção Arte\&Ensino da Editora C/ARTE e membro de AMARTE, FAEB, ANPAP, CLEA e InSEA. Foi Coordenadora Adjunta da área de Artes - Mestrado Profissional na CAPES.

E-mail: luciagpi@gmail.com

Currículo: http://lattes.cnpq.br/3342330120066308

\section{Ana Del Tabor Vasconcelos Magalhães}

Doutoranda em Artes - Programa de Pós-Graduação em Artes da Escola de Belas Artes da Universidade Federal de Minas Gerais - Linha de Pesquisa Artes e Experiências Interartes na Educação. Mestre em Educação pela Universidade da Amazônia (UNAMA), Licenciada em Educação Artística Habilitação em Artes Plásticas, Professora Adjunta da Faculdade de Educação do Instituto de Ciências da Educação ICED/UFPA. Membro da Federação de Arte Educadores do Brasil (FAEB). Membro do Grupo de Pesquisas Ensino de Arte e Tecnologias Contemporâneas/UFMG- (CNPq) e Membro do Grupo de Pesquisa Arte, Memórias e Acervos na Amazônia/UFPA-(CNPq).

E-mail: ana_del@uol.com.br

Currículo: http://lattes.cnpq.br/0310909316607481

Recebido em 26 de maio de 2018 Aceito em 15 de julho de 2018 